\title{
Prevalence and association of the laboulbenialean fungus Hesperomyces virescens (Laboulbeniales: Laboulbeniaceae) on coccinellid hosts (Coleoptera: Coccinellidae) in Kentucky, USA
}

\author{
JAmes D. HARWOOD ${ }^{1}$, CARlo RICCI ${ }^{2}$, Roberto ROMANI ${ }^{2}$, Kevin M. PITZ $^{1}$, Alex WEIR ${ }^{3}$ and John J. OBRYCKI ${ }^{1}$ \\ ${ }^{1}$ Department of Entomology, University of Kentucky, S-225 Agricultural Science Center North, Lexington, KY 40546-0091, USA; \\ e-mail: James.Harwood@uky.edu \\ ${ }^{2}$ Department of Agricultural and Environmental Sciences, Perugia University, Borgo XX Giugno 74, 06121 Perugia, Italy \\ ${ }^{3}$ Faculty of Environmental and Forest Biology, 241 Illick Hall, 1 Forestry Drive, State University of New York College of \\ Environmental Science and Forestry, Syracuse, NY 13210, USA
}

Key words. Insect-associated fungi, Coccinellidae, Laboulbeniales, ectoparasitic fungi

\begin{abstract}
The laboulbenialean fungi occur throughout the world and are closely associated with a range of arthropods, including many coleopteran hosts. Throughout the summer of 2004, coccinellids were collected from a Bluegrass savanna woodland ecosystem, dominated by blue ash Fraxinus quadrangulata and Chinkapin Oak Quercus muehlenbergii, and the adults were examined for the presence of Hesperomyces virescens using binocular and scanning electron microscopy. Over $80 \%$ of adult Harmonia axyridis, a species previously reported as having a persistent association with the fungus, were infected. No significant differences were observed in incidence on male and female hosts, however, the distribution of fungus differed between sexes. Female $H$. axyridis had a greater percentage of infection on their elytron compared to other parts of their body whilst male infection was concentrated around their elytra, legs and abdomen. Although infection rates were significantly lower, we report, for the first time, the presence of this fungus on the hosts Cycloneda munda, Brachiacantha quadripunctata and Psyllobora vigintimaculata. This is the first study documenting the incidence of this insect-associated fungus with these native coccinellids of North America. In the samples collected from the Bluegrass savanna, two species (Coleomegilla maculata and Hyperaspis signata) were not infected by this fungus.
\end{abstract}

\section{INTRODUCTION}

The association of ectoparasitic laboulbenialean fungi with Coleoptera is widely reported (e.g., Weir, 1993, 1994; Weir \& Hammond, 1997; Rossi \& Santamaria, 2000; Garcés \& Williams, 2004; Riddick \& Schaefer, 2005). These obligate, ectoparasitic fungi are estimated to number between 10,000 and 50,000 species worldwide on Coleoptera (Weir \& Hammond, 1997), with smaller numbers associated with other host species in the Acari, Blattodea, Dermaptera, Diplopoda, Diptera, Heteroptera, Hymenoptera, Isoptera, Orthoptera and Thysanoptera. Not only do these Laboulbeniales parasitize many different species, but they occur from the tropics (Rossi \& Santamaria, 2000; Weir \& Rossi, 2001; Zerm \& Adis, 2004) to the sub-Antarctic (Hughes et al., 2004), and on both terrestrial (e.g., Rossi \& Santamaria, 2000, Weir \& Rossi, 2001) and aquatic (Santamaria, 2000, 2004) hosts.

Although some Coccinellidae are reported as hosts of Laboulbeniales (Weir \& Hammond, 1997), relatively few studies document the incidence of their infection on these hosts; for example, they infect Adalia bipunctata (L.) (Weir \& Beakes, 1996, Welch et al., 2001), Olla v-nigrum Casey (Weir \& Beakes, 1996), and Harmonia axyridis (Pallas) (Garcés \& Williams, 2004; Riddick \& Schaefer, 2005). Despite the relatively few reports of insect-host associations between coccinellids and laboulbenialean fungi, the consequence of such interactions, and those with other generalist predators which are known to be important in biological control (Meijer, 1975), could be profound given that some generalist predator communities feed extensively on pest populations in agroecosystems. The Coccinellidae, including $H$. axyridis, are important in the control of many pest species (Obrycki \& Kring, 1998; Koch, 2003; Pervez \& Omkar, 2006) and, as part of an assemblage of natural enemies (Sunderland et al., 1997), are capable of restricting pest population growth. Whilst most laboulbenialean fungi have few detrimental effects on their hosts (Whisler, 1968; Weir \& Beakes, 1995), some negative fitness consequences from these associations are documented (Bro Larsen, 1952; Strandberg \& Tucker, 1974; Gemeno et al., 2004), and have been attributed to causing declines in the summer populations of Chilocorus bipustulatus L. in Israel (Kamburov et al., 1967).

The laboulbenialean fungus, Hesperomyces virescens Thaxter (Laboulbeniales: Laboulbeniaceae) was first reported on Chilocorus stigma (Say) (Thaxter, 1931) and has subsequently been reported on other coccinellids including Hippodamia convergens Guerin-Meneville (Thaxter, 1931), Cycloneda sanguinea (L.) (Tavares, 1979), Adalia bipunctata L. (Weir, 1996), Psyllobora spp. (Tavares, 1985), Eriopis connexa Germar (Thaxter, 1931) and Olla v-nigrum (Mulsant) (Weir \& Beakes, 1996). However, given that historic specimens of exotic coccinellids in the United States contained no individuals with laboulbenialean infection (Harwood et al., 2006), the aim of this study was to examine present-day associations 

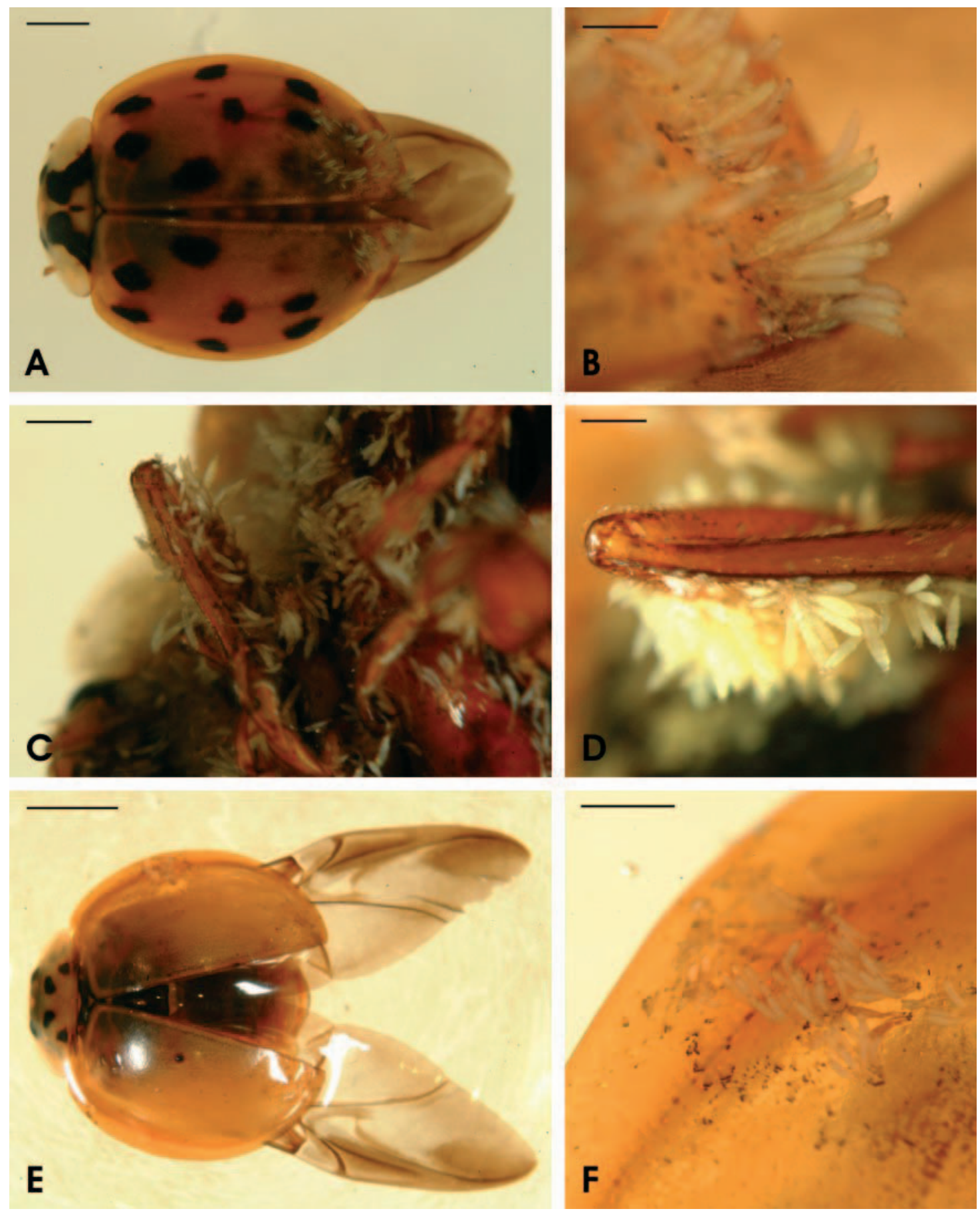

Fig. 1. Harmonia axyridis females infected with Hesperomyces virescens: A - dorsal view of the whole insect with both elytra distally infected; B - high magnification image of A; $\mathrm{C}$ - ventral view of $H$. axyridis female heavily infected with $H$. virescens; $\mathrm{D}$ - leg of $H$. axyridis heavily infected with $H$. virescens; $\mathrm{E}$ - dorsal view of the whole insect with one elytra infected; $\mathrm{F}$ - high magnification image of E. Scale bars: A $-1 \mathrm{~mm}, \mathrm{~B}-200 \mu \mathrm{m}, \mathrm{C}-500 \mu \mathrm{m}, \mathrm{D}-250 \mu \mathrm{m}, \mathrm{E}-1 \mathrm{~mm}, \mathrm{~F}-500 \mu \mathrm{m}$.

between Coccinellidae and Laboulbeniales in nonagricultural habitats. The intention was to quantify these associations and identify new fungal-host interactions between ectoparasitic fungi and both exotic and native coccinellids in the field.

\section{MATERIAL AND METHODS}

Coccinellid adults were collected by trapping in numerous randomly located Townes style (Townes, 1972) Malaise Traps
(Sante Traps, Lexington, KY, USA) at discrete locations within the woodland at Silver Lake Farm, Harrison County, Kentucky, USA. Samples were collected weekly from May until August 2004. The field site is located in the Bluegrass Region of central/northern Kentucky, ranging between approximately 160 and $320 \mathrm{~m}$ above sea level. The habitat is characterized by remnants of ancient Bluegrass savanna, dominated by the blue ash Fraxinus quadrangulata Michx. (Scrophulariales: Oleaceae) and Chinkapin Oak Quercus muehlenbergii Engelm. (Fagales: Fagaceae) with a grass (Festuca sp.) understory. The site also 

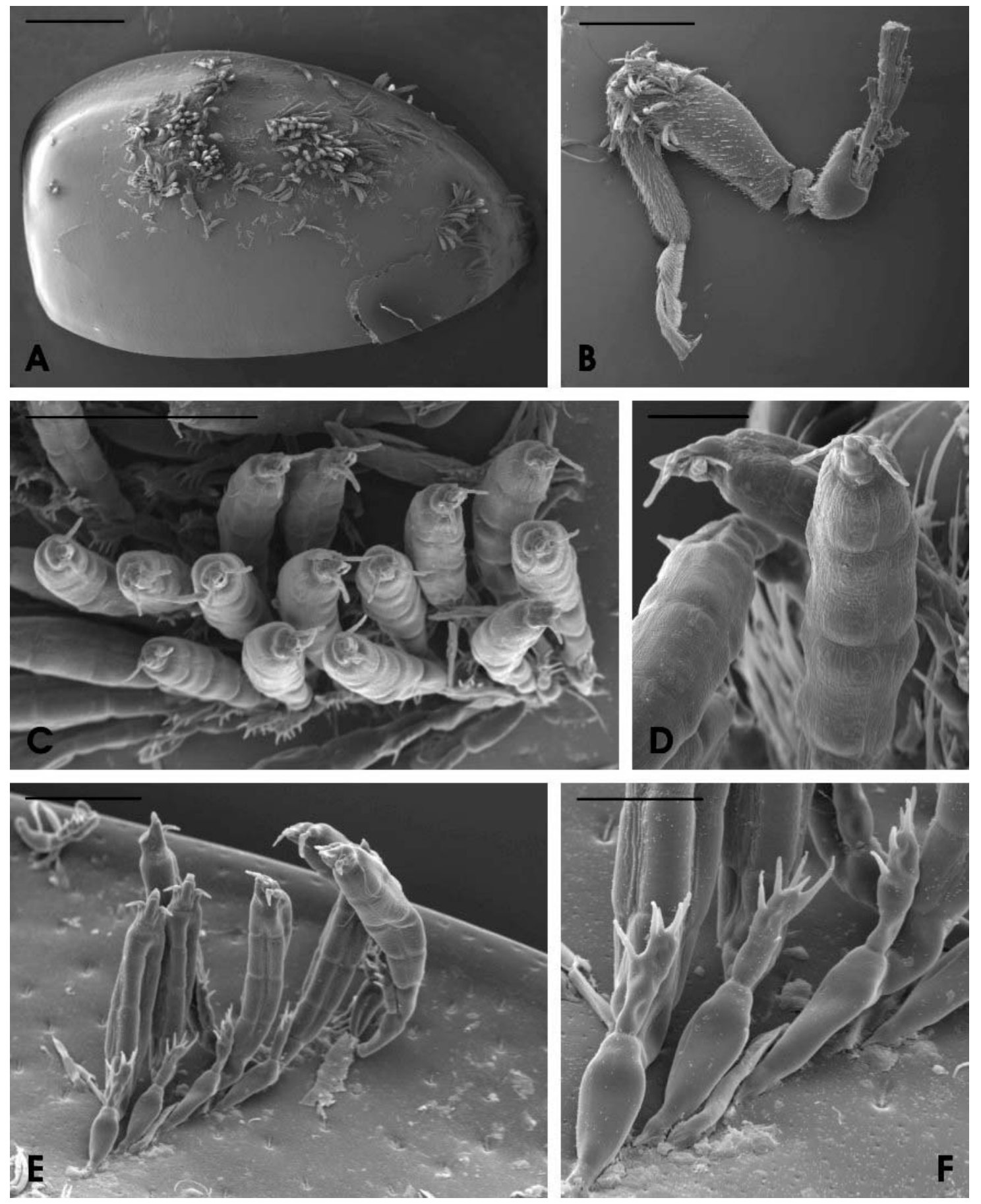

Fig. 2. Scanning electron micrographs (SEM) of Harmonia axyridis females infected with Hesperomyces virescens. A - dorsal view of the right elytron with diffuse fungal infection; $\mathrm{B}$ - fungal infection of the right leg; $\mathrm{C}$ - mycosis of mature $H$. virescens attached to coccinellid elytra showing close spatial arrangement of the fungi; $\mathrm{D}$ - mature $H$. virescens showing the upper portion of the perithecium, including apical outgrowths that may function as "trigger organs" in ascospore discharge; E - mature and developing thalli of $H$. virescens on the elytra; $\mathrm{F}$ - basal portion of developing $H$. virescens showing the antheridial appendage and receptacle. Scale bars: A $-1 \mathrm{~mm}, \mathrm{~B}-1 \mathrm{~mm}, \mathrm{C}-200$ micron, $\mathrm{D}-50$ micron, $\mathrm{E}-100$ micron, $\mathrm{F}-50$ micron.

contains closed-canopy woodlands with an understory consisting of forbes and rye.

Following collection, all species were transferred into 95\% ethanol for subsequent examination for, and identification of, fungal parasites. The presence and distribution of laboulbenialean fungi was examined by binocular microscopy and specieslevel identification of Hesperomyces virescens confirmed due to the morphology of the perithecial apex and wall cells of mature thalli using light- and scanning electron microscopy (SEM) (after Weir \& Beakes, 1996). SEM preparation on five male and female $H$. axyridis and two Cycloneda munda (Say) was undertaken for photographic presentation by initially preserving individuals in alcohol and subsequently completely dehydrating with successively higher concentrations of ethanol $(70 \%, 80 \%$, $90 \%, 95 \%$ and $99 \%$ ). After dehydration, whole insect bodies or parts (i.e. elytra and legs) were critical point dried in a Balzers 
TABLE 1. Number of adult coccinellids collected from a Bluegrass savanna ecosystem, and number infected with the laboulbenialean fungus Hesperomyces virescens.

\begin{tabular}{lccc}
\hline Species & Number collected & Number infected & $\%$ infected \\
\hline Harmonia axyridis & 147 & 121 & 82.3 \\
Psyllobora vigintimaculata & 170 & 8 & 4.7 \\
Brachiacantha quadripunctata & 48 & 2 & 4.2 \\
Cycloneda munda & 81 & 2 & 2.5 \\
Coleomegilla maculata & 59 & 0 & 0 \\
Hyperaspis signata & 23 & 0 & 0 \\
\hline
\end{tabular}

Union $^{\circledR}$ Critical Point Dryer 020 unit (Balzers Union Ltd., Balzers, Liechtenstein), gold coated in a Balzers Union ${ }^{\circledR}$ SCD040 unit (Balzers Union Ltd., Balzers, Liechtenstein), and examined using a Philips ${ }^{\circledR}$ XL 30 scanning electron microscope.

The differences in infection rates between male and female $H$. axyridis were analyzed using a $\chi^{2}$ test (Zar, 1999) by compiling results from individuals into a single sample unit of unreplicated data. The location of infection on $H$. axyridis was also analyzed using a $\chi^{2}$ test on absolute count data of numbers infected followed by a Goodman's post hoc procedure (Marascuilo \& Serlin, 1988) for discerning levels of significance between infection locations.

\section{RESULTS}

The examination of 528 coccinellids under binocular microscope revealed extensive formations of mycosis on Harmonia axyridis (Figs. 1A-F). These mycoses were later identified as thalli of the laboulbenialean fungus $H$.

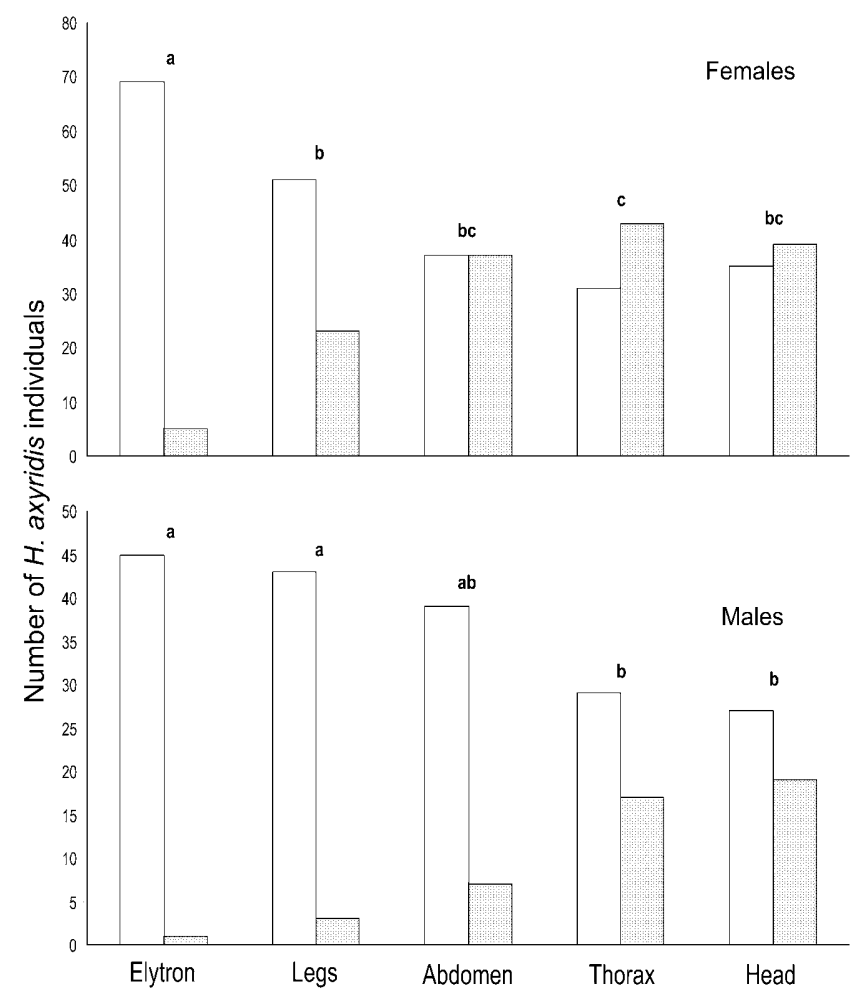

Fig. 3. Distribution of Hesperomyces virescens on different body parts in females and males of Harmonia axyridis. Empty bars represent number of infected individuals; grey bars represent number of uninfected individuals. Columns with the same letter are not different at $P<0.001$. virescens using both light- and scanning electron microscopy (Fig. 2). The fungal infections were predominantly present in a clumped distribution around the distal part of the elytra, but were also recorded on the legs, sternites, thorax and head of infected individuals.

Although $H$. axyridis were heavily infected with these fungal ectoparasites $(82.3 \%$ infected, Table 1$)$, three other coccinellids were collected (C. munda, Psyllobora vigintimaculata (Say) and Brachiacantha quadripunctata Melsheimer) in which infection rates were much lower (Table 1). Two species, Hyperaspis signata (Olivier) and Coleomegilla maculata (De Geer), were not observed to be hosts for this fungus (Table 1). Interestingly, despite the high prevalence of $H$. virescens on $H$. axyridis hosts, there was no significant difference in infection rates between males $(78 \%$ infected $)$ and females $(85 \%$ infected) $\left(\chi^{2}=1.279, d f=1, P=0.258\right)$. No other invertebrates captured in Malaise traps at this field site were identified as hosts of $H$. virescens.

Analysis of fungal infection rates indicated non-random distribution of $H$. virescens on $H$. axyridis (females: $\chi^{2}=$ 35.73, $d f=4, P<0.001$; males: $\chi^{2}=54.81, d f=4, P<$ $0.001)$ with greater fungal infection on the elytron of females compared to all other body parts (Fig. 3a). The distribution of fungal infection differed in males, with a high prevalence of $H$. virescens on the legs, abdomen and elytron (Fig. 3b).

\section{DISCUSSION}

The high levels of infection of Hesperomyces virescens on their coccinellid hosts indicated the potential for detrimental fitness consequences resulting from such associations if this laboulbenialean fungus negatively impacts its hosts. Harmonia axyridis, a species previously reported as being susceptible to infection by this laboulbenialean fungus in host populations in Ohio (Garcés \& Williams, 2004) and Pennsylvania (Riddick \& Schaefer, 2005), was also highly parasitized in this study. However, infection rates of male and female $H$. axyridis did not vary despite considerable between-gender differences reported in these previous studies. Clear differences in the distribution of infection existed between males and females. These differences, with a greater incidence of $H$. virescens on the dorsal surface of the elytron of females and high incidence on the ventral surface (legs and abdomen) of males suggest sexual transmission may be operating in these hosts. Riddick \& Schaefer (2005) also reported the likelihood for non-sexual transmission of laboulbenialean 
fungi between hosts. Similar distribution patterns are documented here whereby the high infection rates on the dorsal surface of males, and the incidence on the ventral surface of females, suggested that other non-sexual forms of contact may be operating in dispersing this fungus.

This high prevalence of $H$. virescens on $H$. axyridis could therefore be due to the large overwintering aggregations (Nalepa et al., 1996; Schaefer, 2003) thus increasing levels of host-to-host contact, given that transmission of this ectoparasitic fungus is believed to occur primarily by direct contact between an infected and uninfected individual (De Kesel, 1995). If such aggregations facilitate an increased spread of the fungus between hosts, which could ultimately affect the density and growth of coleopteran populations (De Kesel, 1993), changes in population structure may occur. However, without the long-term monitoring of coccinellid populations and laboratory evaluation of fitness consequences resulting from these infections, it is difficult to confirm this hypothesis. Interestingly, Coleomegilla maculata, another coccinellid which overwinters in large aggregated communities (Benton \& Crump, 1979) below ground or under leaf litter, thus avoiding direct contact with $H$. axyridis, showed no incidence of fungal infection suggesting that $H$. virescens is not entirely generalist in terms of host susceptibility. However, despite relatively low infection rates, the first association with a number of other coccinellids (Cycloneda munda, Brachiacantha quadripunctata and Psyllobora vigintimaculata) is reported here. Further experiments are therefore required to ascertain the consequence of exposure to this ectoparasitic fungus and determine whether infection influences the long-term fitness of these hosts, given the common assumption that no negative fitness consequences result from associations with laboulbenialean fungi.

ACKNOWLEDGEMENTS. We would like to thank J. Roden, C. Lindsay and A. Sharkey for their assistance with the sorting of samples from Malaise Traps, A. Bonomi for help checking specimens in the laboratory, G. Salerno for help with statistical analysis and two anonymous referees for their valuable suggestions to the manuscript. J. Harwood and J. Obrycki are supported by the Kentucky Agricultural Experiment Station State Project KY099004 and the collecting was undertaken by funds provided by NSF ATOL grant number EF-0337220. SEM pictures were taken using the Electron Microscopy Center, Perugia University (CUME). This is publication number 05-08-036 of the Kentucky Agricultural Experiment Station.

\section{REFERENCES}

Benton A.H. \& CRUmp A.J. 1979: Observations on aggregation and overwintering in the coccinellid beetle Coleomegilla maculata (De Geer). J. N. Y. Entomol. Soc. 87: 154-159.

Bro LARSEN E. 1952: On subsocial beetles from the salt-marsh, their care of progeny and adaptation to salt and tide. Trans. IX Int. Congr. Entomol., Amsterdam 1: 502-506.

De Kesel A. 1993: Relations between host population density and spore transmission of Laboulbenia slackensis (Ascomycetes, Laboulbeniales) from Pogonus chalceus (Coleoptera, Carabidae). Belg. J. Bot. 126: 155-163.
De Kesel A. 1995: Relative importance of direct and indirect infection in the transmission of Laboulbenia slackensis (Ascomycetes, Laboulbeniales). Belg. J. Bot. 128: 124-130.

Garcés S. \& Williams R. 2004: First record of Hesperomyces virescens Thaxter (Laboulbeniales: Ascomycetes) on Harmonia axyridis (Pallas) (Coleoptera: Coccinellidae). $J$. Kansas Entomol. Soc. 77: 156-158.

Gemeno C.L., Zurek L. \& Schal C. 2004: Control of Hesperomyces spp. (Ascomycetes: Laboulbeniales) infection in the wood cockroach, Parcoblatta lata (Dictyoptera: Blattodea: Blattellidae), with benomyl. J. Invert. Pathol. 85: 132-135.

Harwood J.D., Ricci C., Romani R. \& Obrycki J.J. 2006: Historic prevalence of a laboulbenialean fungus infecting introduced coccinellids in the United States. Antenna 30: 74-79.

Hughes M., Weir A., Leschen R., Judd C. \& Gillen B. 2004: New species and records of Laboulbeniales from the subantarctic islands of New Zealand. Mycologia 96: 1355-1369.

Kamburov S.S., Nadel D.J. \& Kenneth R. 1967: Observations on Hesperomyces virescens Thaxter (Laboulbeniales), a fungus associated with premature mortality of Chilocorus bipustulatus L. in Israel. Israel J. Agric. Res. 17: 131-134.

Koch R.L. 2003: The multicolored Asian lady beetle, Harmonia axyridis: a review of its biology, uses in biological control and non-target impacts. J. Insect Sci. 3:32: 1-16. Available online: insectscience.org/3.32.

Marasculio L.A. \& Serlin R.C. 1988: Statistical Methods for the Social and Behavioral Sciences. W.H. Freeman \& Company, New York.

MeIJER J. 1975: Carabid (Coleoptera, Carabidae) migration studied with Laboulbeniales (Ascomycetes) as biological tags. Oecologia 19: 99-103.

NalePa C.A., KidD K.A. \& Ahlstrom K.R. 1996: Biology of Harmonia axyridis (Coleoptera: Coccinellidae) in winter aggregations. Ann. Entomol. Soc. Am. 89: 681-685.

OBRYCKI J.J. \& KRING T.J. 1998: Predaceous Coccinellidae in biological control. Annu. Rev. Entomol. 43: 295-321.

Pervez A. \& OmKar 2006: Ecology and biological control application of multicolored Asian ladybird, Harmonia axyridis: a review. Biocontr. Sci. Technol. 16: 111-128.

Riddick E.W. \& Schaefer P.W. 2005: Occurrence, density and distribution of parasitic fungus Hesperomyces virescens (Laboulbeniales: Laboulbeniaceae) on multicolored Asian lady beetle (Coleoptera: Coccinellidae). Ann. Entomol. Soc. Am. 98: 615-624.

Rossi W. \& SANTAMARIA S. 2000: New Laboulbeniales parasitic on Staphylinidae. Mycologia 92: 786-791.

SANTAMARIA S. 2000: Taxonomy and morphology of Amorphomyces (Laboulbeniales). Mycol. Res. 104: 1389-1398.

SANTAMaria S. 2004: Two new genera of Laboulbeniales allied to Zodiomyces. Mycologia 96: 761-772.

SCHAEFER P.W. 2003: Winter aggregation of Harmonia axyridis (Coleoptera: Coccinellidae) in a concrete observation tower. Entomol. News 114: 23-28.

StrandBerg J.O. \& Tucker L.C. 1974: Filariomyces forficulae Shanor occurrence and effects on the predatory earwig, Labidura riparia (Pallas). J. Invert. Pathol. 24: 357-364.

Sunderland K.D., Axelsen J.A., Dromph K., Freier B., Hemptinne J.-L., Holst N.H., Mols P.J.M., Petersen M.K., Powell W., Ruggle P., Triltsch H. \& Winder L. 1997: Pest control by a community of natural enemies. Acta Jutl. 72: 271-326.

TAVAres I.I. 1979: The Laboulbeniales and their arthropod hosts. In Batra L.R. (ed.): Insect-fungus Symbiosis, Nutrition, 
Mutualism, and Commensalism. Wiley, New York, pp. 229-258.

TAVARes I.I. 1985: Laboulbeniales (Fungi, Ascomycetes). Mycol. Mem. 9.J. Cramer Publishing, Stuttgart, Germany.

THAXTER R. 1931: Contribution towards a monograph of the Laboulbeniaceae. V. Mem. Am. Acad. Arts Sci. 16: 1-435.

Townes H. 1972: A light-weight Malaise trap. Entomol. News 18: $239-247$.

WeIR A. 1993: Rare and interesting Laboulbeniales on Sudanese Coleoptera. Mycol. Res. 97: 509-512.

WEIR A. 1994: Further records of Laboulbeniales from collections of British Coleoptera. Mycol. Res. 98: 433-444.

WeIR A. 1996: A preliminary host-parasite list of British Laboulbeniales (Fungi, Ascomycotina). Entomologist 115: $50-58$.

Weir A. \& BeAKes G.W. 1995: An introduction to the Laboulbeniales: a fascinating group of entomogenous fungi. Mycologist 9: 6-10.

Weir A. \& Beakes G.W. 1996: Correlative light- and scanning electron microscope studies on the developmental morphology of Hesperomyces virescens. Mycologia 88: 677-693.
Weir A. \& Hammond P.M. 1997: Laboulbeniales on beetles: host utilization patterns and species richness of the parasites. Biodivers. Conserv. 6: 701-719.

WeIr A. \& Rossi W. 2001: New and interesting Bolivian Laboulbeniales. Mycologia 93: 171-180.

Welch V.L., Sloggett J.J., Webberley K.M. \& Hurst G.D.D. 2001: Short-range clinal variation in the prevalence of a sexually transmitted fungus associated with urbanization. Ecol. Entomol. 26: 547-550.

WHISLER H.C. 1968: Experimental studies with a new species of Stigmatomyces (Laboulbeniales). Mycologia 60: 65-75.

ZAR J.H. 1999: Biostatistical Analysis. Prentice Hall, Upper Saddle River, NJ, 663 pp.

Zerm M. \& Adis J. 2004. Seasonality of Laboulbenia phaexanthae (Ascomycota, Laboulbeniales) and its host Phaexantha aequinoctialis (Coleoptera, Carabidae) at a central Amazonian blackwater floodplain. Mycol. Res. 108: 590-594.

Received January 13, 2006; revised and accepted April 25, 2006 